\title{
Mathematical Modeling and Simulation on the Stimulation Interactions in Coalbed Methane Thermal Recovery
}

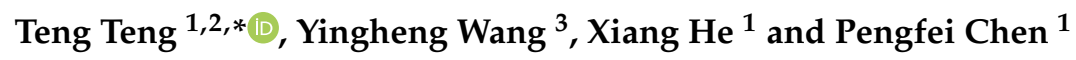 \\ 1 School of Energy and Mining Engineering, China University of Mining and Technology, \\ Beijing 100083, China \\ 2 State Key Laboratory of Coal Resources and Safe Mining, China University of Mining and Technology, \\ Beijing 100083, China \\ 3 School of Electronics and Information Engineering, Tongji University, Shanghai 201804, China \\ * Correspondence: T.Teng@cumtb.edu.cn
}

Received: 26 June 2019; Accepted: 6 August 2019; Published: 8 August 2019

\begin{abstract}
Heat stimulation of coalbed methane (CBM) reservoirs has remarkable promotion to gas desorption that enhances gas recovery. However, coalbed deformation, methane delivery and heat transport interplay each other during the stimulation process. This paper experimentally validated the evolutions of gas sorption and coal permeability under variable temperature. Then, a completely coupled heat-gas-coal model was theoretically developed and applied to a computational simulation of CBM thermal recovery based on a finite element approach of COMSOL with MATLAB. Modeling and simulation results show that: Although different heat-gas-coal interactions have different effects on CBM recovery, thermal stimulation of coalbed can promote methane production effectively. However, CBM thermal recovery needs a forerunner heating time before the apparent enhancement of production. The modeling and simulation results may improve the current cognitions of CBM thermal recovery.
\end{abstract}

Keywords: coalbed methane thermal recovery; thermal stimulation interaction; heat-gas-coal model; modeling and simulation

\section{Introduction}

Coalbed methane (CBM) is a cleaner and cheaper resource among the fossil fuels [1-3]. It is reported that the accumulated reserve of Chinese CBM is about 10 billion cubic meters, and the recoverable resource represents about 47\% [4]. In earlier years, CBM is treated as a nerve-wracking hazard in coal mining. However, people's attitudes are changing that CBM becomes an efficiently and environmentally friendly fuel now. However, the production of CBM meets a great challenge of lower reservoir permeability and higher methane sorption capacity in China. A survey research shows that the permeability of Chinese coal ranges from $1 \times 10^{-4} \mathrm{mD}$ to $1 \times 10^{-3} \mathrm{mD}$ while it ranges from $0.1 \mathrm{mD}$ to $1 \mathrm{mD}$ of American or Australian coal [5]. As a result, the traditional direct-recovery method of CBM cannot satisfy the demands of effective production. Therefore, researchers and engineers in this field tried some unconventional methods by using a series of manual treatments to the methane reservoirs, such as the fracturing by water and gas, the displacement of adsorption by carbon dioxide and the stimulation of increasing temperature.

Thermal stimulation to deep CBM reservoirs is an effective method to promote gas recovery. Researchers have explored many different basic theories and mining technologies [6-10]. Before the production of methane, water with high temperature of $80{ }^{\circ} \mathrm{C}$ is assumed to be injected into a hypothetical CBM reservoir to causes helpful coal-gas interactions [11]. The simulation results indicate 
that the reservoir temperature increases $30^{\circ} \mathrm{C}$ in twelve years to finally expand the methane production by $58 \%$ compared to the conventional method of direct recovery. Li et al. [12] established a mathematical model before demonstrating the complicated couplings among coalbed, methane and temperature. The model was then applied to a CBM thermal recovery of microwave heating. Research results show that thermal stimulation with microwave expands methane recovery more than $40 \%$ due to the deformation induced by gas sorption. Khoshnevis et al. [13] investigated the synergy type of gas production by injecting geothermal water. They established a three-dimension model to discuss the production potential of gas field and the influences of injection rate, reservoir permeability, saturation condition on the ultimate methane production. Lu [14] proposed a numerical simulation of heat injection into a three-dimensional temperature field by ANSYS to evidence the increasing production of CBM with temperature due to the easier desorption with higher temperature. Shahtalebi et al. [15] point out that the costs in coalbed methane thermal production limit the economic effectiveness. Only when the price of natural gas is comparatively higher and the demand for clean energy is stronger, the method of thermal production can become an economically attractive option.

CBM thermal recovery benefits a lot from the enhanced gas adsorption behavior [16-18]. Sakurovs et al. [19] presented three sets of experimental sorption evolutions at variable temperature. The results show that the methane adsorption capacity has great dependency with coal temperature. The sorption of coal to methane at different temperature ranges may indicate different behaviors, and a traditional Langmuir equation cannot describe the different trends. For example, Guan et al. [20,21] estimated the adsorption isotherms at temperatures from $283 \mathrm{~K}$ to $343 \mathrm{~K}$. They find that the adsorption capacity of CBM decreases linearly with increasing temperature at the range of $283 \mathrm{~K}$ to $323 \mathrm{~K}$, and keeps constant at the range of $323 \mathrm{~K}$ to $343 \mathrm{~K}$. Similarly, Crosdale et al. [22] also observed the influence of temperature on gas desorption. Besides, at temperature lower that $30^{\circ} \mathrm{C}$, the adsorption capacity is averagely elevated by $10 \%$, where it has no significant influences at the temperatures that higher than $60{ }^{\circ} \mathrm{C}$. After a series of detailed theoretical and experimental research, Zhang et al. [23] concluded that the hysteresis degree was to be influenced by the microstructures of coal, especially the surface area. Further, Liu et al. [24] find that the influence of temperature on methane adsorption is more remarkable in coals that have smaller pores rather than larger pores. The adsorption capacity of methane decreases by approximately $19 \%, 32 \%$ and $45 \%$ for coals at micro-pore with sizes of $0.7-0.9 \mathrm{~nm}, 1.0-1.3 \mathrm{~nm}$ and size that larger than $1.4 \mathrm{~nm}$ respectively. Although many researchers have pointed out the effects of temperature on gas sorption, a theoretical presentation based on experiments that can concisely and usefully describe the effects is still lack.

Change of reservoir temperature causes a succession of interactions to CBM seepage behavior and the evolution of coal permeability [25-27]. Wang et al. [28] found that the evolution of coalbed permeability with increasing temperature may be divided into two stages: coal permeability decreases due to the internal swelling of coal matrix at the first stage and increases at the domination of rising gas pressure. Li et al. [12] performed a set of thermo-hydro-mechanical experiments to observe coal permeability by a servo-controlled equipment. The results indicate that evolutions of coal permeability with rising temperature are closely related with coal deformation. Yin et al. [29] goes further to observe the changing of coal permeability at different deformation stages. Coal permeability decreases with the rising temperature remarkably before the peak deformation, and it keeps almost constant after the peak deformation. That is because the growth of fractures in coal has more influences than the temperature on coal permeability. Focusing on the fractured bituminous coal, Perera et al. [30] investigated the permeability evolution under five different temperatures that ranges from $25^{\circ} \mathrm{C}$ to $70{ }^{\circ} \mathrm{C}$. The testing result shows that the $\mathrm{CO}_{2}$ permeability increases linearly with temperature when coal temperature is higher than $90^{\circ} \mathrm{C}$ due to the temperature-sensitive sorption behavior of $\mathrm{CO}_{2}$. Besides, temperature change causes thermal expansion and fracturing [31]. Teng et al. explored the mechanism of these coal-gas interactions and tried to establish a permeability model for methane flow under thermo-hydro-mechanical situations. To conclude, one can find that, the above experimental 
results are mainly qualitative, it is necessary to propose a theoretically permeability model that can better connect the experimental rules with CBM thermal production.

CBM thermal recovery donates a multi-physical issue of coal, gas and heat [32,33]. Abed et al. [34] described a thermo-hydro-mechanical (THM) framework that suitable for modeling the behavior of unsaturated soils and rock. Due to the CBM thermal recovery method of microwave heating, Gao et al. [35] illustrated the interactions among temperature field, coalbed compaction, and methane transfer. According to their thermo-hydro-mechanical model developed in a finite element environment, higher stimulation temperature results in larger recovery radius. Fan et al. [36] discussed the competitive sorption of carbon dioxide with methane and its interactions with water under a thermo-hydro-mechanical-chemical condition. A two-phase-flow model was developed for $\mathrm{CO}_{2}$ enhanced CBM recovery. Xia et al. [37] established a coupled hydro-thermo-mechanical model for the spontaneous combustion of underground coal and quantitatively predicted the spontaneous combustion locations of Dongtan coal mine. These precursor works have enlightening meanings for the study of multi-physical interactions in CBM thermal recovery. However, a fully coupled heat-gas-coal model is still necessary.

Following on our previous establishment of coal permeability model, this paper developed a completely coupled heat-gas-coal model for deep CBM thermal recovery by considering the interactions among coalbed deformation, methane delivery and heat transport. To evaluate these interactions among three physical fields and the production efficiency of CBM recovery, a numerical simulation using the finite element approach was validated. Finally, a series of analysis work based on the modeling and simulation are carried out.

\section{Experimental Observation of Methane Sorption Under Variable Temperature}

\subsection{Experimental Program}

In this section, the sorption characteristics of coal to pure $\mathrm{CH}_{4}$ under variable temperature is observed in a self-developed gas adsorption apparatus, see Figure 1. Coal samples that acquired from the exploratory borehole of Jinjia lignite mine China are powdered into size of $150 \mu \mathrm{m}$. The experimental temperature varies from $25^{\circ} \mathrm{C}$ to $85^{\circ} \mathrm{C}$, concretely $25^{\circ} \mathrm{C}, 45^{\circ} \mathrm{C}, 65^{\circ} \mathrm{C}$ and $85^{\circ} \mathrm{C}$ as representatives. At each temperature, the adsorption content was tested in a pressure vessel at the pressure that increases from the atmospheric pressure to a maximum of $10 \mathrm{MPa}$.

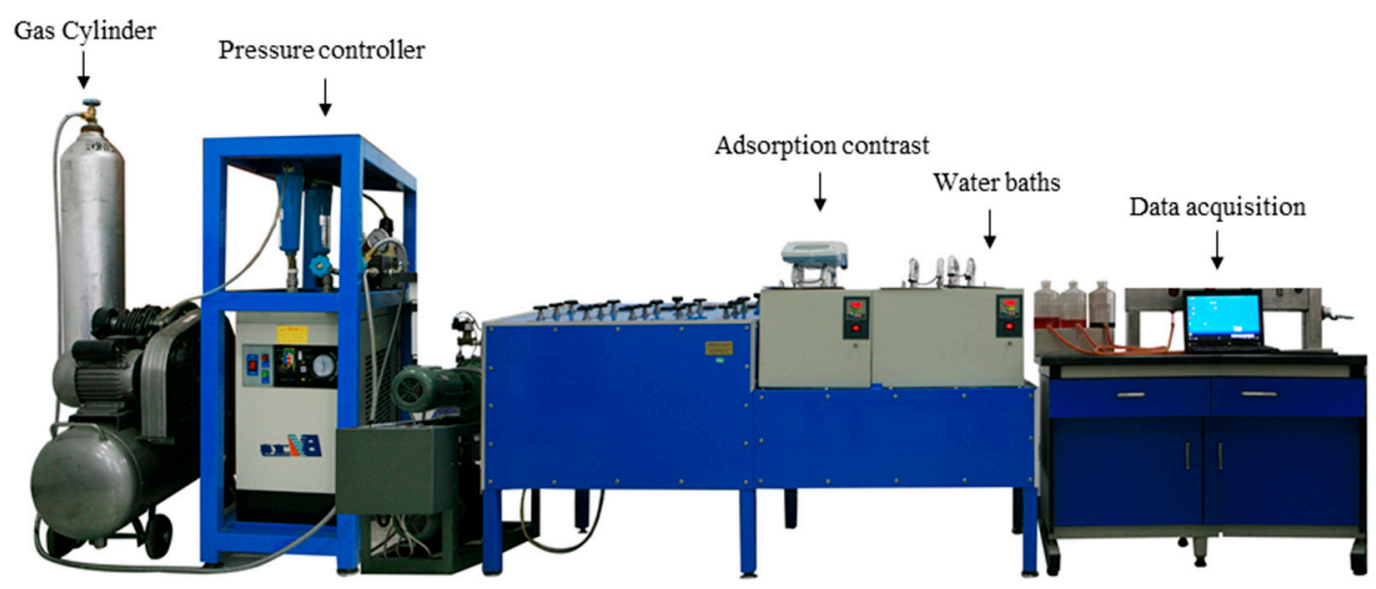

Figure 1. A self-developed isothermal gas adsorption apparatus.

\subsection{Effects of Temperature on Methane Adsorption Content}

The directly observed methane adsorption content under variable temperature is represented by the colorful spots in Figure 2. One can obtain that temperature has a significant influence on the adsorption capacity of Jinjia lignite. For example, when the temperature increases from $25^{\circ} \mathrm{C}$ to 
$45^{\circ} \mathrm{C}, 65^{\circ} \mathrm{C}$ and $85^{\circ} \mathrm{C}$, the adsorption content at pressure of $10 \mathrm{MPa}$ decreases $14.1 \%, 22.5 \%, 30.3 \%$, respectively. It is because that the surface free energy of coal decreases when the temperature increases, as a result more $\mathrm{CH}_{4}$ is released from the micro-pore.

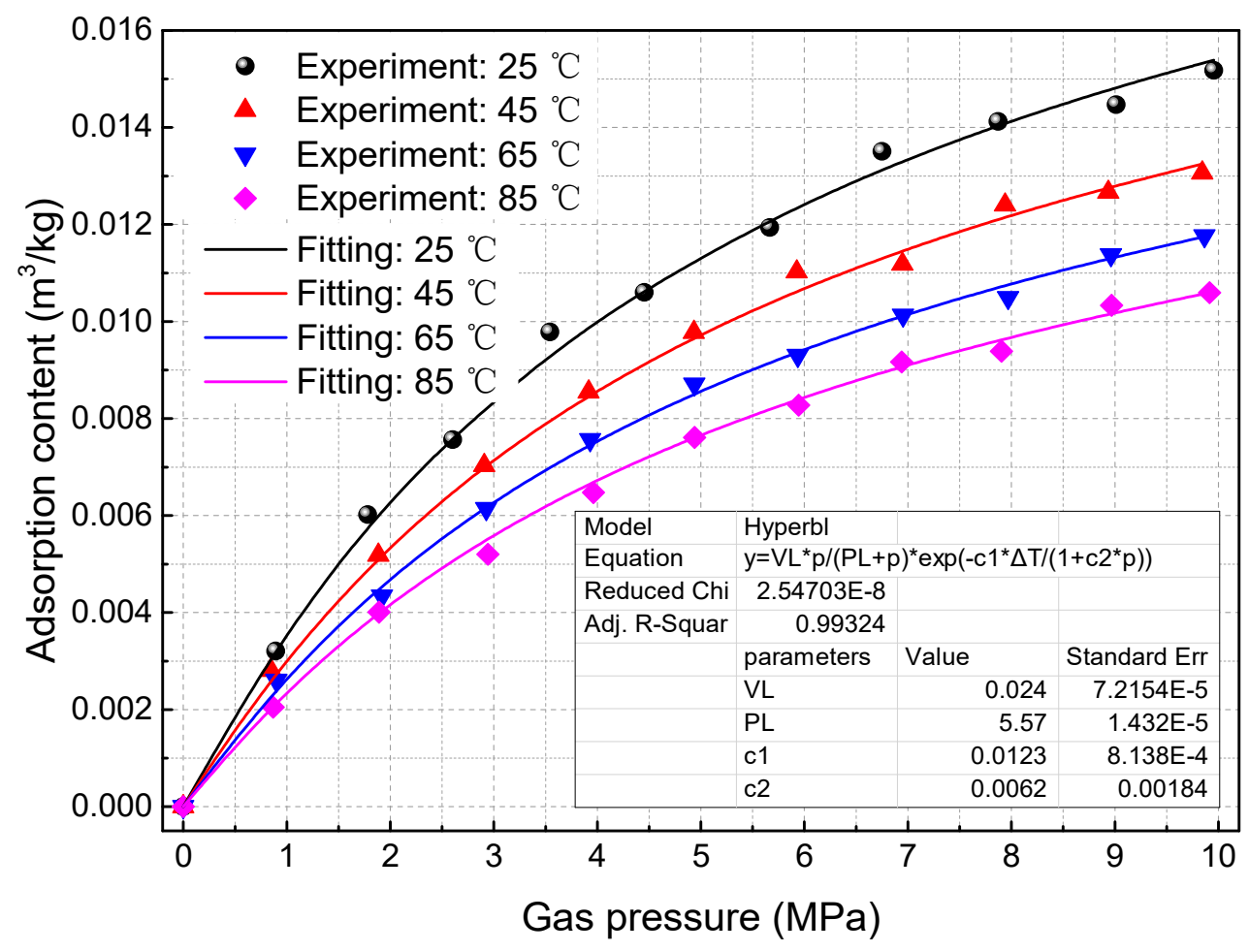

Figure 2. Validation of temperature modified Langmuir equation.

A Langmuir equation is often used to describe the methane adsorption content under constant temperature [38-40] as:

$$
V_{s g}=V_{L} \frac{b p}{1+b p}
$$

where, $V_{s g}$ is the methane adsorption content, $\mathrm{m}^{3} / \mathrm{kg}, V_{L}$ and $b$ donate the Langmuir volume and pressure constants.

However, Equation (1) must be modified if the temperature changes. Here, an additional exponential term is introduced to revise the equation as:

$$
V_{s g}=\frac{V_{L} p}{P_{L}+p} \exp \left[-\frac{c_{2}\left(T-T_{r e f}\right)}{1+c_{1} p}\right]
$$

where, $P_{L}$ donates the Langmuir pressure constant, Pa. $T_{r e f}$ is the reference temperature for methane sorption, $\mathrm{K} . c_{1}$ and $c_{2}$ are the coefficients for pressure and temperature, $\mathrm{Pa}^{-1}$ and $\mathrm{K}^{-1}$, respectively. Figure 2 also shows the validation results of Equation (2) by the obtained experimental data. The well match of the fitting curves with the experimental results indicates that the modified Langmuir Equation (2) can effectively describe the evolution of methane sorption under variable temperature. This domino effect of gas sorption with changeable temperature indicates useful implication for CBM thermal recovery. 


\subsection{Volumetric Stain Induced by Methane Desorption}

Coal matrix expands when it adsorbs gas. According to [41], the gas sorption-induced volumetric strain has a linear relationship with the gas adsorption content as:

$$
\varepsilon_{s}=\alpha_{s g} V_{s g}
$$

where $\alpha_{s g}$ is the expansion coefficient.

Thus, the volume deformation of coal caused by methane adsorption at different temperature can be expressed as:

$$
\varepsilon_{s}=\frac{\alpha_{s g} V_{L} p}{P_{L}+p} \exp \left(-\frac{c_{2} \Delta T}{1+c_{1} p}\right)-\frac{\alpha_{s g} V_{L} p_{0}}{P_{L}+p_{0}}
$$

where $\Delta T=T-T_{0}$ shows the change of temperature.

\section{Mathematical Model}

Thermal recovery of CBM is a coupled process of coalbed deformation, methane delivery and heat transport. Among these three fields, one affects another. For example, the compaction of coalbed block causes the reduction of coal porosity and permeability for gas flow while the decrease of methane pressure changes the effective stress to promote coalbed deformation. Moreover, thermal expansion that caused by temperature change affects both coal deformation and gas flow. Following section is to establish a completely coupled heat-gas-coal model for CBM thermal recovery by considering the interactions among coalbed deformation, methane flow and heat transport. Before any derivation, coalbed is assumed as one kind of homogeneous, isotropic continuum while methane is treated as ideal gas. Methane transport in porous coalbed is treated as a Darcy's flow.

\subsection{Coalbed Deformation Equation}

Based on rock elasticity theory, the deformation of coal reservoir can be governed by a Navier-type equilibrium equation. In this paper, the equilibrium equation is optimized by the variable temperature [42] as:

$$
G u_{i, k k}+\frac{G}{1-2 v} u_{k, k i}-\alpha \cdot p_{, i}-K \varepsilon_{s, i}-K \alpha_{T} T_{, i}+F_{i}=0
$$

in which $F_{i}$ and $p$ represent the body force of coal and the pressure of methane, MPa. $G=0.5 E /(1+v)$ and $K=E /(3(1-2 v))$ are the shear and bulk modulus, respectively. $E$ and $v$ represent the elasticity modulus and Poisson's ratio, respectively. $\alpha=1-K / K_{s},(\alpha<1)$ means the Biot's coefficients, where $K_{s}$ donates the modulus of coal grains.

The volumetric stain that induced by temperature change is defined $[43,44]$ as:

$$
\varepsilon_{T}=\alpha_{T} \Delta T
$$

where, $\alpha_{T}$ is the thermal expansion coefficient, $\mathrm{K}^{-1}$.

\subsection{Methane Flow Equation}

The CBM flow in reservoirs obeys a mass conservation equation [37]:

$$
\frac{\partial m}{\partial t}+\nabla \cdot\left(\rho_{g} v_{g}\right)=Q_{s}
$$


in which $Q_{s \kappa}$ represents the methane source. $v_{g}$ is the velocity vector of flow, $\mathrm{m} / \mathrm{s} ; m$ is the content of methane in coalbed that can be expressed as:

$$
m=\rho_{g} \phi+\rho_{c} \rho_{g a} \frac{V_{L} p}{P_{L}+p} \exp \left[-\frac{c_{2}\left(T-T_{r e f}\right)}{1+c_{1} p}\right]
$$

where, the first and second terms represent the free and adsorbed components, respectively. $\phi$ is the porosity of coal, $\rho_{c}$ represents coal density while $\rho_{g a}$ represents the methane density at standard conditions. The real gas density can be expressed as:

$$
\rho_{g}=\frac{M_{g} p}{R T}
$$

in which, $R$ donates the universal gas constant and $M_{g}$ means the molar mass.

Darcy's velocity vector $v_{g}$ in Equation (7) is proportional to the pressure gradient $\nabla p$ and permeability $k$ :

$$
v_{g}=\frac{-k}{\mu} \cdot \nabla p
$$

where $\mu$ represents the viscosity coefficient of methane.

Following on our previous work [31], the permeability of coalbed can be expressed as:

$$
\frac{k}{k_{0}}=\left(\frac{\phi}{\phi_{0}}\right)^{3}=\left\{1-\frac{3 K}{\phi_{0} K+3 K_{f}}\left[\left(\varepsilon_{s}+\varepsilon_{T}-\varepsilon_{v}\right)-\left(\varepsilon_{s 0}+\varepsilon_{T 0}\right)\right]\right\}^{3}
$$

in which, $K_{f}$ donates the equivalent modulus of coal fracture. Volume strain $\varepsilon_{v}$ that induced by effective stress is expressed as:

$$
\varepsilon_{v}=\frac{1}{K}(\bar{\sigma}+\alpha p)+\varepsilon_{s}+\varepsilon_{T}
$$

in which, $\bar{\sigma}$ is the mean stress of coal.

Substituting Equations (4)-(6) into Equation (12), the permeability model reads as

$$
\frac{k}{k_{0}}=\left(\frac{\phi}{\phi_{0}}\right)^{3}=\left\{1-\frac{3 K}{\phi_{0} K+3 K_{f}}\left[\left(\frac{\alpha_{s g} V_{L} p}{P_{L}+p} e^{-\frac{c_{2} \Delta T}{1+c_{1} p}}+\alpha_{T} \Delta T-\varepsilon_{v}\right)-\frac{\alpha_{s g} V_{L} p_{0}}{P_{L}+p_{0}}\right]\right\}^{3}
$$

In the experimental testing of coal permeability, Equation (13) can be modified as:

$$
\frac{k}{k_{0}}=\left(\frac{\phi}{\phi_{0}}\right)^{3}=\left\{A-B e^{-C \Delta T}-D \Delta T\right\}^{3}
$$

where,

$$
\begin{gathered}
A=1-\frac{3 K \varepsilon_{v}}{\phi_{0} K+3 K_{f}}-\frac{\alpha_{s g} V_{L} p_{0}}{P_{L}+p_{0}} \\
B=\frac{3 K}{\phi_{0} K+3 K_{f}} \frac{\alpha_{s g} V_{L} p}{P_{L}+p} \\
C=\frac{c_{2}}{1+c_{1} p} \\
D=\frac{3 K \alpha_{T}}{\phi_{0} K+3 K_{f}}
\end{gathered}
$$

Figure 3 shows the fitting results of the experimental data [30] by the proposed permeability model. Table 1 lists the fitting parameters of Equation (14). The matching result shows that the proposed coal permeability model can be well used to describe the evolution of coal permeability under variable temperature. 


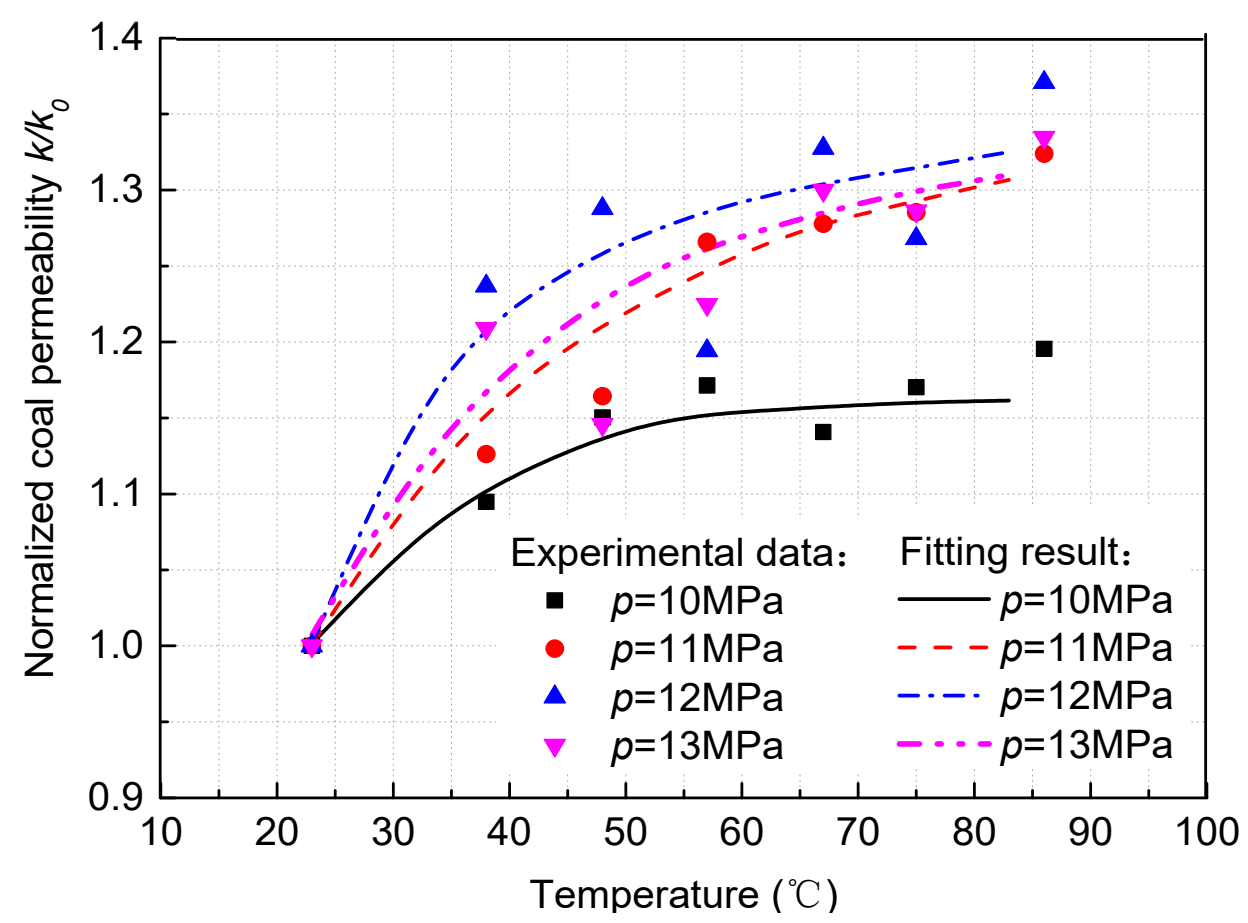

Figure 3. Validation of coal permeability model with experimental data.

Table 1. Fitting parameters for coal permeability evolution.

\begin{tabular}{ccccccc}
\hline \multirow{2}{*}{ Coal Samples } & \multicolumn{5}{c}{ Fitting Parameters } \\
\cline { 3 - 7 } & & A & B & C & D & $\mathbf{R}^{2}$ \\
\hline \multirow{2}{*}{ Gas } & 10 & $5.00 \times 10^{-2}$ & 0.09 & $6.14 \times 10^{-4}$ & $1.05 \times 10^{-5}$ & 0.915 \\
pressure & 11 & $4.92 \times 10^{-2}$ & 0.11 & $8.23 \times 10^{-4}$ & $1.03 \times 10^{-5}$ & 0.854 \\
(MPa) & 12 & $4.83 \times 10^{-2}$ & 0.08 & $7.01 \times 10^{-4}$ & $1.16 \times 10^{-5}$ & 0.975 \\
& 13 & $4.76 \times 10^{-2}$ & 0.10 & $1.50 \times 10^{-3}$ & $1.50 \times 10^{-5}$ & 0.962 \\
\hline
\end{tabular}

Substituting Equations (8)-(13) into Equation (7), we can obtain the methane flow equation:

$$
\begin{aligned}
& \left\{\frac{\phi}{T}-\frac{N \varepsilon_{L} p}{T} \cdot \exp \left(-\frac{c_{2}\left(T-T_{r e f}\right)}{1+c_{1} p}\right) \cdot\left[\frac{P_{L}}{\left(P_{L}+p\right)^{2}}+\frac{p}{P_{L}+p} \cdot \frac{c_{1} c_{2}\left(T-T_{r e f}\right)}{\left(1+c_{1} p\right)^{2}}\right]\right\} \frac{\partial p}{\partial t} \\
& +\left\{\frac{N \varepsilon_{L} p}{T} \cdot \exp \left(-\frac{c_{2}\left(T-T_{r e f}\right)}{1+c_{1} p}\right) \cdot\left[\frac{p}{P_{L}+p} \cdot \frac{c_{2}}{\left(1+c_{1} p\right)^{2}}\right]-\frac{\phi p}{T^{2}}-\frac{N p}{T}\left[\alpha_{T}+\frac{\vartheta \phi_{o}}{\left(1-\vartheta\left(T-T_{0}\right)\right)^{2}}\right]\right\} \frac{\partial T}{\partial t} \\
& +\nabla \cdot\left(-\frac{k p}{\mu T} \nabla p\right)+\nabla \cdot\left[-D \nabla\left(\frac{p}{T} \phi\right)\right]+\frac{N p}{T} \frac{\partial \varepsilon_{v}}{\partial t}=0
\end{aligned}
$$

in which, $N=3 \phi_{0} K /\left(\phi_{0} K+3 K_{f}\right)$.

\subsection{Heat Transport Equation}

The conservation of energy for CBM thermal recovery obeys an equilibrium [45] as:

$$
\frac{\partial\left(C_{e q} T\right)}{\partial t}+\nabla\left(-K_{e q} \nabla T\right)+p \nabla \cdot v_{g}+K \alpha_{T} T \frac{\partial \varepsilon_{v}}{\partial t}=Q_{T}
$$

in which, the specific heat capacity of coalbed reads:

$$
C_{e q}=\phi \rho_{g} C_{g}+(1-\phi) \rho_{c} C_{c}
$$


$K_{e q}$ is the effective thermal conductivity. $C_{g}$ and $C_{c}$ represent the specific heat coefficients for methane and coal. $Q_{T}$ is the heat source.

Combining Equation (18) with Equation (17), one gets the modified conservation equation of energy as:

$$
C_{e q} \frac{\partial T}{\partial t}+p \nabla \cdot\left(-\frac{k}{\mu} \nabla p\right)+K \alpha_{T} T \frac{\partial \varepsilon_{v}}{\partial t}=K_{e q} \nabla^{2} T+\rho_{g} C_{g} \frac{k}{\mu} \nabla p \nabla T
$$

The Equations (5), (16) and (19) make up a completely coupled heat-gas-coal model. The mathematical model is used in simulating CBM thermal production.

\section{Modeling on CBM thermal Recovery}

Figure 4 chooses a modeling and simulation domain to represent a half area of CBM thermal recovery from the research of Shahtalebi et al. [15]. Based on a partial-differential-equation solver of COMSOL with MATLAB that runs on Windows 10 environment with Intel Core i7-6500U and RAM 16.0 GB hardware, the simulator is implemented in 1049 s. In Figure 4, the simulation domain consists of 4208 elements. The computation time is $10^{9} \mathrm{~s}$ that are derived into 100 steps.

The length and width of the simulation domain are one hundred meters and forty meters, respectively. The depth of methane recovery well into coalbed is seventy meters. A thermal stimulation well in size of thirty meters locates in the center. For the CBM reservoir, the initial methane pressure and temperature are $3.5 \mathrm{MPa}$ and $298 \mathrm{~K}$, respectively. For coal deformation, the boundary $\mathrm{AB}$ and $\mathrm{BC}$ are confined to normal force of 15 and $8 \mathrm{MPa}$, while the boundary $\mathrm{AD}$ and $\mathrm{CD}$ are constrained by normal displacement. For gas flow, the boundary $\mathrm{AB}, \mathrm{BC}, \mathrm{CD}$ and $\mathrm{DE}$ are symmetric boundary with no flow, while $\mathrm{AE}$ is common pressure boundary of $0.1 \mathrm{MPa}$. For heat transfer, the boundary $\mathrm{AB}, \mathrm{BC}$, $\mathrm{CD}$ and DA are thermal insulation, while FG is common temperature boundary of $373 \mathrm{~K}$. To contrast simulation results, comparison sites, no. 1, 2, 3 and 4, are pre-set. Other simulation parameters are listed in Table 2.

Table 2. Parameters used in simulation of coalbed methane thermal recovery.

\begin{tabular}{cccc}
\hline Variable & Parameter & Value Used & Sources \\
\hline$E$ & Young's modulus of coal, $(\mathrm{MPa})$ & 2713 & {$[45]$} \\
$E_{s}$ & Young's modulus of coal grains, $(\mathrm{MPa})$ & 4070 & {$[45]$} \\
$\nu$ & Poisson's ratio of coal & 0.339 & {$[45]$} \\
$\rho_{c}$ & Density of coal, $\left(\mathrm{kg} / \mathrm{m}^{3}\right)$ & $1.25 \times 10^{3}$ & {$[41]$} \\
$\rho_{g a}$ & Density of gas at standard condition, $\left(\mathrm{kg} / \mathrm{m}^{3}\right)$ & 0.717 & - \\
$\varepsilon_{L}$ & Sorption coefficient for volumetric strain, $\left(\mathrm{kg} / \mathrm{m}^{3}\right)$ & 0.0156 & {$[41]$} \\
$k_{0}$ & Initial permeability of coal, $(\mathrm{mD})$ & 0.001 & {$[31]$} \\
$\phi_{0}$ & Initial porosity of coal & 0.02 & Given \\
$\mu$ & Dynamic viscosity coefficient of gas, $(\mathrm{Pa} \cdot \mathrm{s})$ & $1.84 \times 10^{-5}$ & {$[41]$} \\
$V_{L}$ & Langmuir volume constant, $\left(\mathrm{m}^{3} / \mathrm{kg}\right)$ & 0.048 & {$[46]$} \\
$P_{L}$ & Langmuir pressure constant, $(\mathrm{MPa})$ & 1.57 & {$[46]$} \\
$c_{1}$ & Pressure coefficient, $(\mathrm{MPa}-1)$ & 0.07 & {$[44]$} \\
$c_{2}$ & Temperature coefficient, $(\mathrm{K}-1)$ & 0.02 & {$[44]$} \\
$T_{a}$ & Temperature at standard condition, $(\mathrm{K})$ & 273 & - \\
$T_{0}$ & Temperature of coal seam, $(\mathrm{K})$ & 298 & $\mathrm{Given}$ \\
$p_{0}$ & Initial value of gas pressure, $(\mathrm{MPa})$ & 3.5 & Given \\
$p_{a}$ & Pressure at standard condition, $(\mathrm{MPa})$ & 0.103 & - \\
$\alpha_{T}$ & Thermal expansion coefficient, $\left(\mathrm{K}^{-1}\right)$ & $2.4 \times 10^{-5}$ & {$[45]$} \\
$C_{c}$ & Specific heat capacity of coal, $(\mathrm{kJ} /(\mathrm{kg} \cdot \mathrm{K}))$ & 1.25 & {$[44]$} \\
$C_{g}$ & Specific heat capacity of gas, $(\mathrm{kJ} /(\mathrm{kg} \cdot \mathrm{K}))$ & 1.62 & {$[44]$} \\
$K_{e q}$ & Effective thermal conductivity of coal, $(\mathrm{J} /(\mathrm{m} \cdot \mathrm{s} \cdot \mathrm{K}))$ & 0.2 & {$[44]$} \\
\hline
\end{tabular}




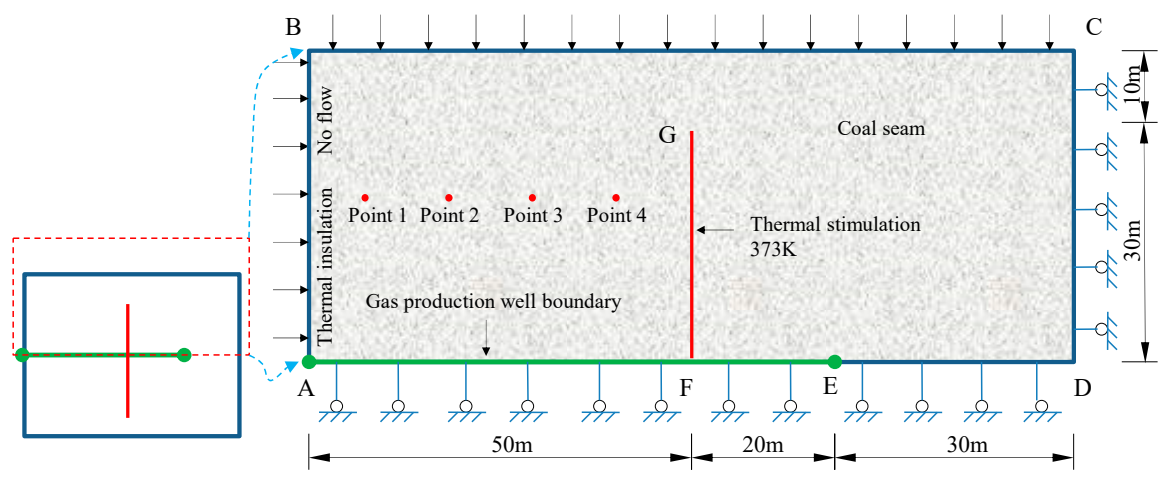

Figure 4. Numerical simulation model.

\section{Modeling Results}

\subsection{Distribution of Coalbed Temperature}

Figures 5 and 6 show the contour distribution of temperature in reservoirs during CBM thermal recovery, especially the temperature at four observation points.

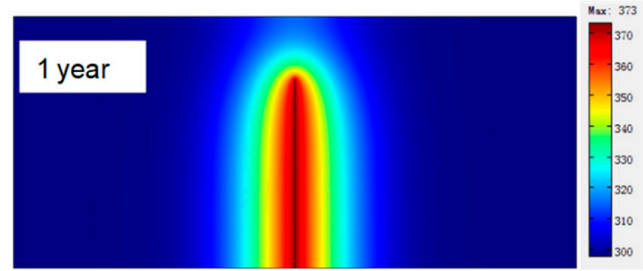

(a) temperature distribution after 1 year

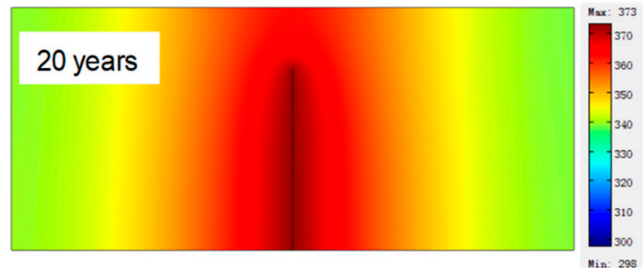

(c) temperature distribution after 20 years

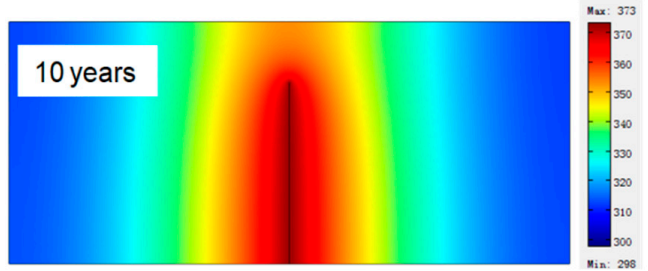

(b) temperature distribution after 10 years

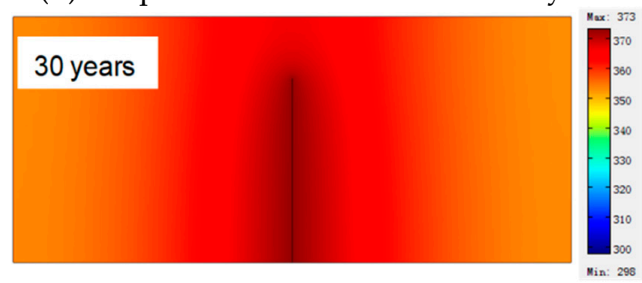

(d) temperature distribution after 30 years

Figure 5. Distribution of coal temperature $(\mathrm{K})$ after different production years.

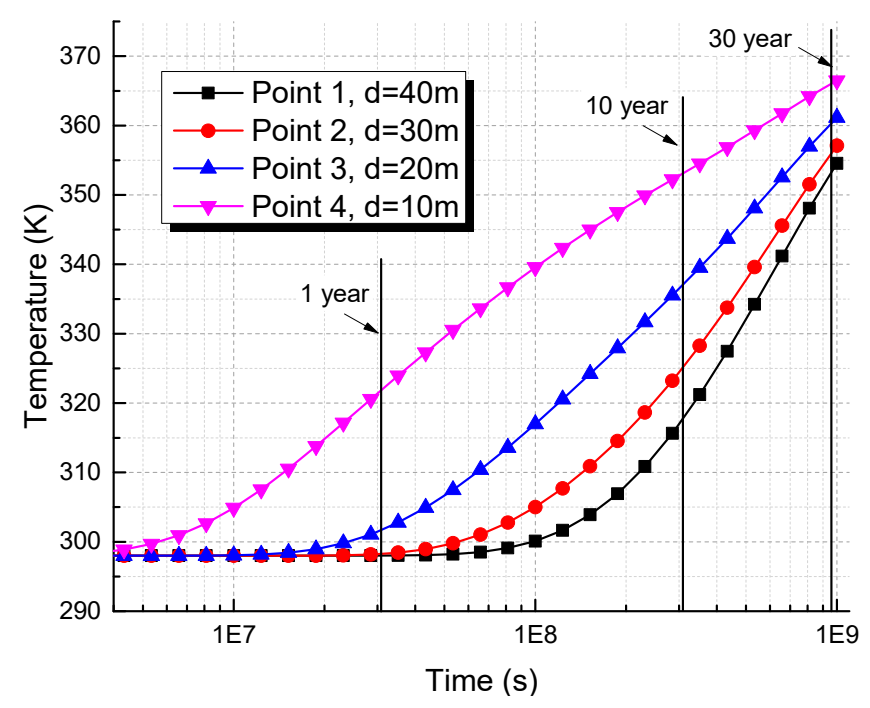

Figure 6. Evolution of reservoir temperature $(\mathrm{K})$ at different observation sites. 
From the figures, one can obviously find that the larger distances from thermal stimulation well correspond to lower increment of reservoir temperature. For earlier years, temperature change is only confined to the vicinity of thermal well. It indicates that CBM thermal recovery needs a long period of heating time to get beneficial output. For example, after one year (about $3 \times 10^{7} \mathrm{~s}$ ), the reservoir temperature keeps almost it initial temperature, the temperature at point 4 is $320 \mathrm{~K}$ while the temperatures at point 3, 2 and 1 are lower than $300 \mathrm{~K}$. However, when the heating time is longer than 10 years, obvious increment of temperature is observed in each observation point. After a heating time of 30 years, the reservoir temperature is higher than $350 \mathrm{~K}$.

\subsection{Evolution of Methane Pressure}

The distribution of methane pressure in reservoirs changes a lot during CBM thermal recovery. It can be seen from the contour distribution of methane pressure after 1, 10, 20 and 30 years in Figure 7 that the methane pressure decreases in the first 10 years. From the figure, we can easily find that the mean gas pressure is about $2.1 \mathrm{MPa}$ after 10 years recovery, whereas $0.65,0.33$ and $0.24 \mathrm{MPa}$ after 20,30 and 40 years.

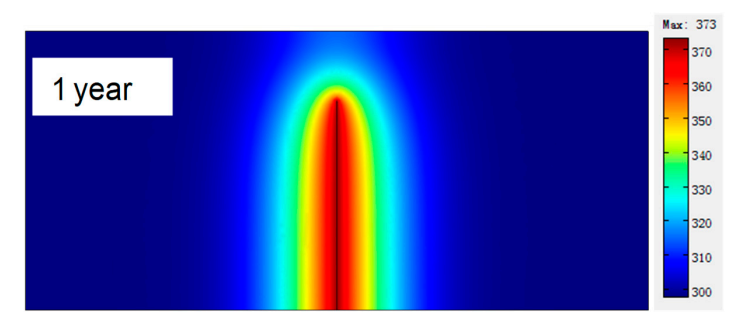

(a) distribution of gas pressure after1 year

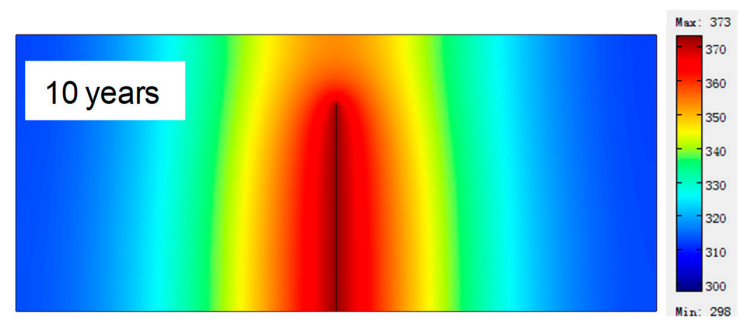

(b) distribution of gas pressure after10 years

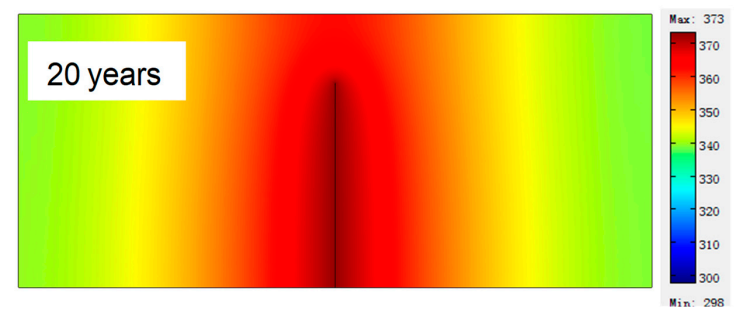

(c) distribution of gas pressure after 20 years

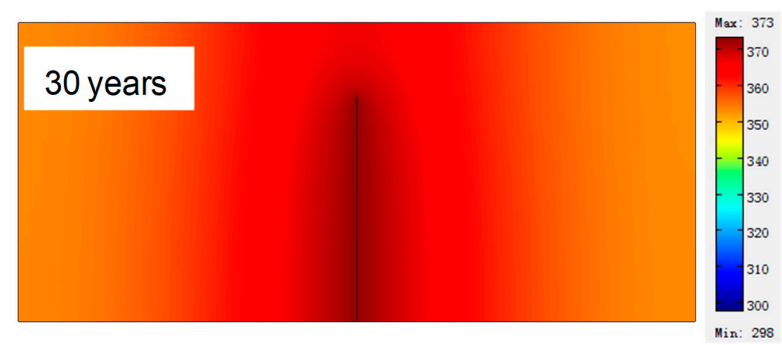

(d) distribution of gas pressure after 30 years

Figure 7. Distribution of gas pressure (MPa) after different production times. 
According to the state equation of ideal gas, higher temperature leads to a higher gas pressure in a confined space. Figure 7 shows that higher coalbed temperature doesn't have prominent domination to methane pressure in reservoirs, even in the area near the thermal stimulation source. This is because the CBM is not confined in coal blocks seriously, but strongly transported out from the narrow fracture network.

\subsection{Evolution of Coalbed Permeability}

Figure 8 shows the evolution of coalbed permeability at different comparison sites. From the figure, one can draw two conclusions. The first is that coal permeability enlargers firstly and then decreases a little tiny bit. The second is that the permeability ratio increases with the decreasing distance from thermal stimulation well. Further, the normalized permeability ratio enlargers to the maximal value of about 1.53 firstly and then decreases. Although the evolution trends of normalized permeability ratio at 4 different observation points are similar, the corresponding production time node for the maximum permeability ratio delays with the increasing distance from the heat injection well, circumstantiate $8 \times 10^{8}, 7 \times 10^{8}, 5 \times 10^{8}$ and $2 \times 10^{8} \mathrm{~s}$, respectively. From Equation (8), and the numerical results of Figures 6 and 8 , one can explain the permeability evolution trend as that the accelerative effect of thermal desorption due to increased temperature plays a dominant role in enlarging coal permeability in the increasing stage, however the effective stress induced coal compaction gradually takes over the dominant role to reduce coal permeability in the decreasing stage where the reservoir temperature is stabilized.

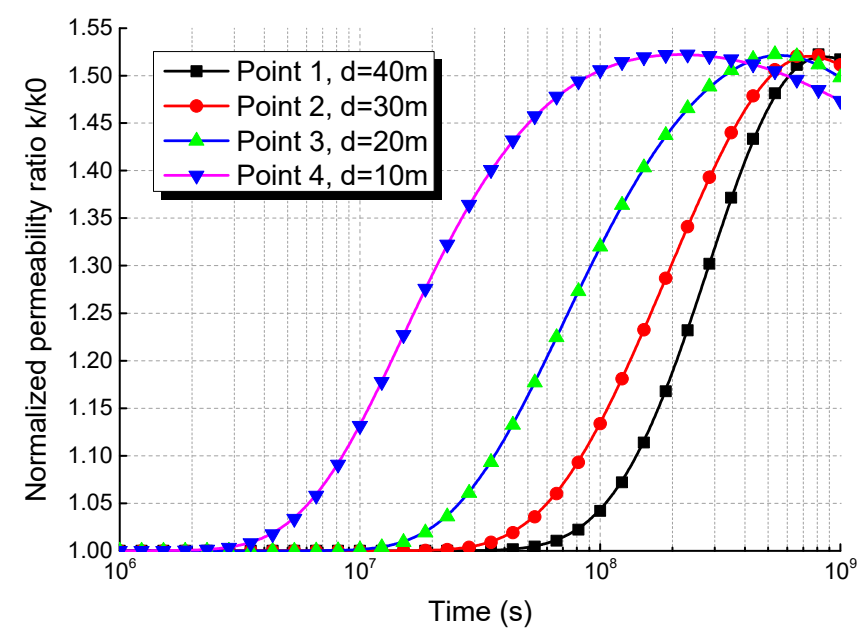

Figure 8. Evolution of coal permeability at different observation sites.

\subsection{Methane Production with Different Thermal Stimulation Temperature}

Figure 9a,b show the cumulative methane production and recovery efficiency in CBM thermal recovery cases with different stimulation temperatures. From the cumulative production, one can conclude that the thermal recovery with higher stimulation temperature has greater promotion to the final production of methane. However, the equal increment of coalbed temperature generates a larger promoting efficiency at lower temperature level due to the great enhancement of temperature to methane desorption. Figure $9 \mathrm{~b}$ shows the efficiency of the increasing yield of coalbed methane thermal production. From the figure, one can see that the maximum production efficiencies of methane with stimulation temperatures of $50{ }^{\circ} \mathrm{C}, 75^{\circ} \mathrm{C}$ and $100{ }^{\circ} \mathrm{C}$ are enlarged by $20 \%, 30 \%$ and $33 \%$ respectively compared with the conversional production method. However, Figure $9 \mathrm{~b}$ also indicates that thermal recovery of coalbed methane needs a forerunner heating time to obtain apparent enhancement of production. 


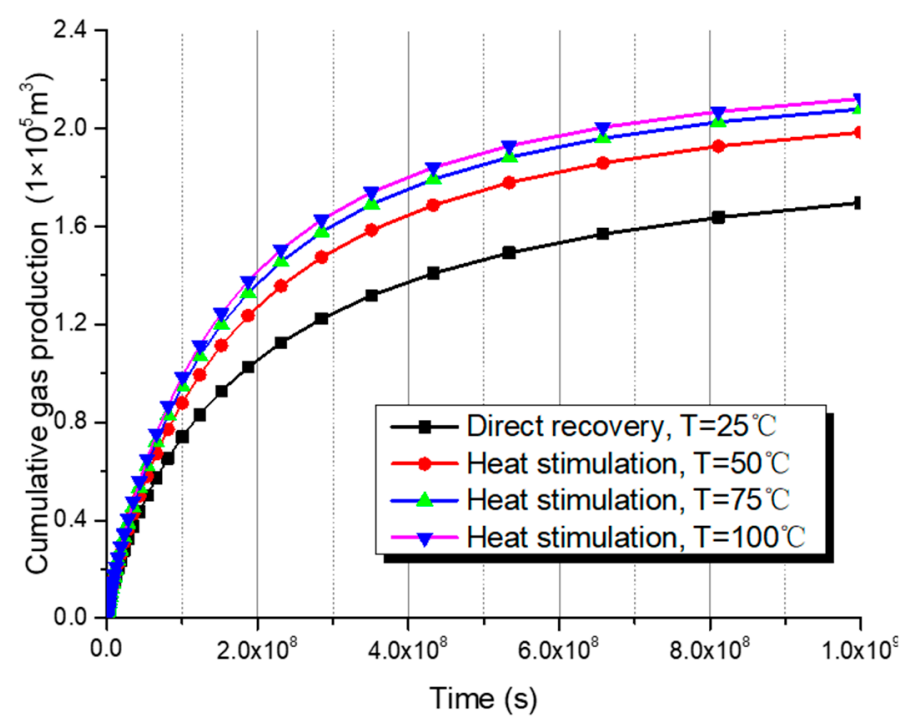

(a) Cumulative production.

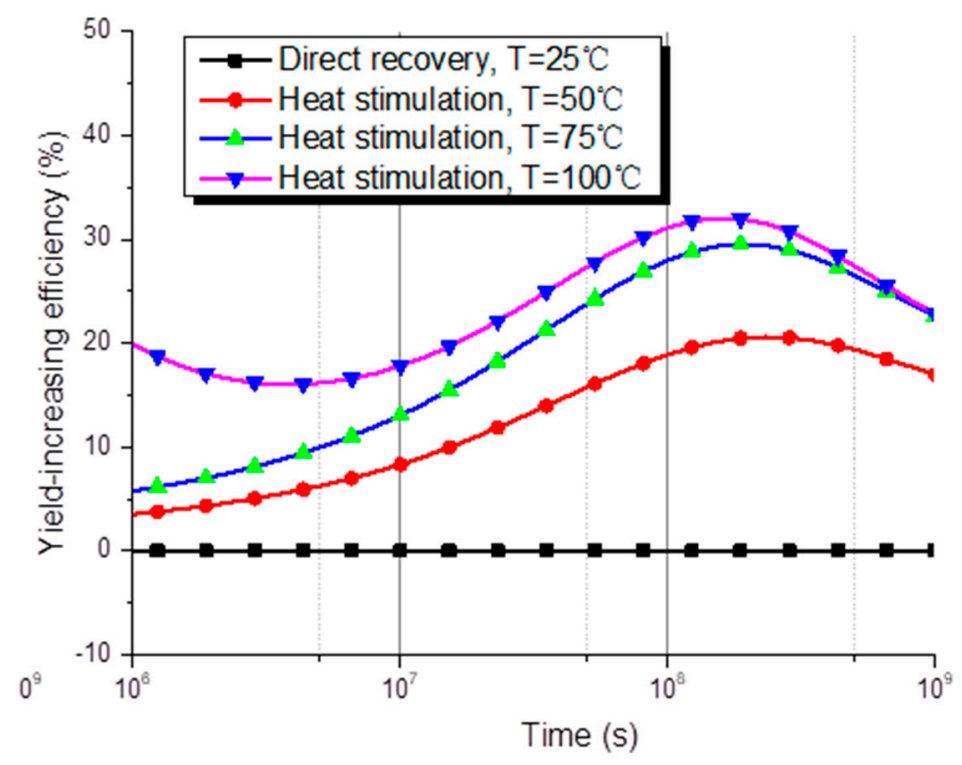

(b) production efficiency.

Figure 9. Gas production with different stimulation temperatures.

\subsection{Methane Production with Different Initial Permeability}

To evaluate the effects of initial reservoirs permeability on CBM thermal recovery, five numerical cases with different permeability and consistent stimulation temperature of $100^{\circ} \mathrm{C}$ are carried out. Evolutions of total methane production are shown in Figure 10a. We can conclude that the methane production enlargers exponentially with production time. To measure the production efficiency, we define an index of output proportion as a percentage of cumulative production to total content of reservoir. Figure 10b shows the evolution of production time with the initial permeability when the output proportion percentage takes value of $25 \%, 50 \%, 75 \%$ and $90 \%$, respectively. From Figure 10, one can obtain that larger value of initial permeability represents higher methane production in earlier time. For example, it takes 17 and 0.5 years respectively to recover $75 \%$ content of the total reserve when the reservoir permeability is $5 \times 10^{-19} \mathrm{~m}^{2}$ and $5 \times 10^{-17} \mathrm{~m}^{2}$, respectively. 


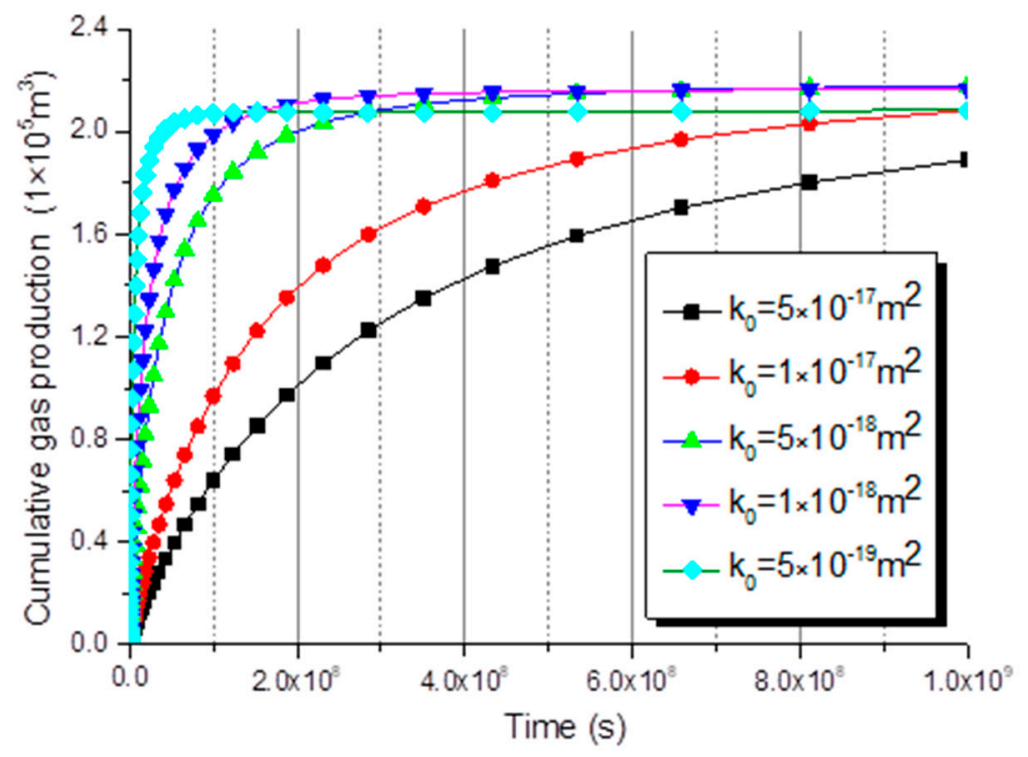

(a) Cumulative production.

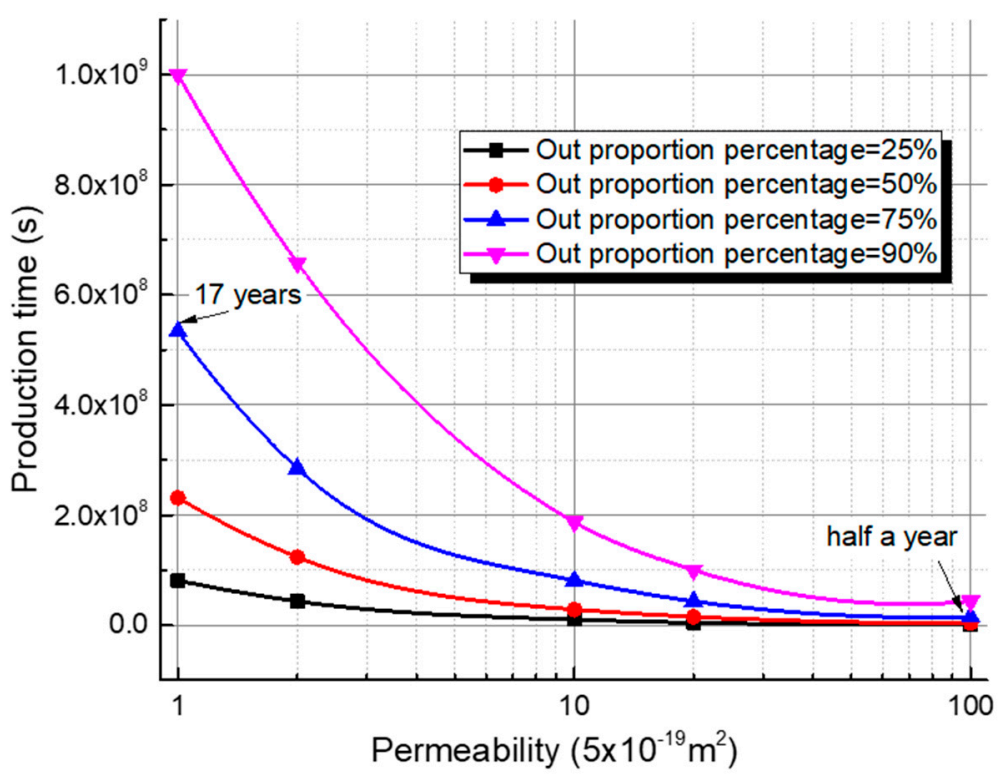

(b) production time for different output proportion

Figure 10. Gas production with different initial reservoir permeability.

\section{Conclusions}

Methane adsorption and coal permeability decrease with increasing temperature. This paper experimentally validated the evolutions of gas sorption and coal permeability under variable temperature. It also established a completely coupled heat-gas-coal model including multi-physics of coalbed deformation, methane delivery and heat transport. The mathematical model was applied to a computational simulation of CBM thermal recovery and solved by COMSOL with MATLAB in a finite element approach environment. To evaluate the thermal recovery process and the production efficiency, a series of analysis work were carried out. The results show that: (1) Thermal stimulation with higher temperature contributes to greater promotion to CBM recovery production. However, it needs a forerunner heating time before an apparent enhancement of production. (2) The normalized coal permeability ratio increases to the maximal value of about 1.53 firstly, and then decreases slightly. 
The corresponding production time node for the maximum permeability ratio delays with the distance from thermal stimulation well. This completely coupled heat-gas-coal model can improve the current understandings of coalbed methane thermal recovery.

Author Contributions: T.T. established the model and performed the numerical simulation; X.H. wrote the original draft preparation; Y.W. and P.C. revised the paper.

Funding: This research was funded by the financial support from the National Natural Science Foundations of Jiangsu (Grant No. BK20170457) and the National key research and development plan (2016YFC0600705).

Conflicts of Interest: The authors declare no conflict of interest.

\section{References}

1. Al-Jubori, A.; Johnston, S.; Boyer, C.; Lambert, S.W.; Bustos, O.A.; Pashin, J.C.; Wray, A. Coalbed methane: Clean energy for the world. Oilfield Rev. 2009, 21, 4-13.

2. Yuan, L. Theory and practice of integrated coal production and gas extraction. Int. J. Coal Sci. Technol. 2015, 2, 3-11. [CrossRef]

3. Towler, B.; Firouzi, M.; Underschultz, J.; Rifkin, W.; Garnett, A.; Schultz, H.; Witt, K. An overview of the coal seam gas developments in Queensland. J. Nat. Gas Sci. Eng. 2016, 31, 249-271. [CrossRef]

4. Zhou, F.; Xia, T.; Wang, X.; Zhang, Y.; Sun, Y.; Liu, J. Recent developments of coal mine methane extraction and utilization in china: A review. J. Nat. Gas Sci. Eng. 2016, 31, 437-458. [CrossRef]

5. Noack, K. Control of gas emissions in underground coal mines. Int. J. Coal Geolo. 1998, 35, 57-82. [CrossRef]

6. Slastunov, S.V.; Prezent, G.M.; Kolikov, K.S. Experimental work on methane recovery at the Lenin Mine of the Karaganda Basin. J. Min. Sci. 1999, 35, 531-535. [CrossRef]

7. Mutyala, S.; Fairbridge, C.; Paré, J.J.; Bélanger, J.M.; Ng, S.; Hawkins, R. Microwave applications to oil sands and petroleum: A review. Fuel Process. Technol. 2010, 91, 127-135. [CrossRef]

8. Singh, A.K.; Baumann, G.; Henninges, J.; Görke, U.J.; Kolditz, O. Numerical analysis of thermal effects during carbon dioxide injection with enhanced gas recovery: A theoretical case study for the Altmark gas field. Environ. Earth Sci. 2012, 67, 497-509. [CrossRef]

9. Wang, H.; Ajao, O.; Economides, M.J. Conceptual study of thermal stimulation in shale gas formations. J. Nat. Gas Sci. Eng. 2014, 21, 874-885. [CrossRef]

10. Xue, L.; Dai, C.; Wang, L.; Chen, X. Analysis of Thermal Stimulation to Enhance Shale Gas Recovery through a Novel Conceptual Model. Geofluids 2019, 2019. [CrossRef]

11. Salmachi, A.; Haghighi, M. Feasibility study of thermally enhanced gas recovery of coal seam gas reservoirs using geothermal resources. Energy Fuels 2012, 26, 5048-5059. [CrossRef]

12. Li, B.; Yang, K.; Xu, P.; Xu, J.; Yuan, M.; Zhang, M. An experimental study on permeability characteristics of coal with slippage and temperature effects. J. Pet. Sci. Eng. 2019, 175, 294-302. [CrossRef]

13. Khoshnevis, N.; Khosrokhavar, R.; Nick, H.; Bruhn, D.F.; Bruining, H. Injection of disposal water from a geothermal reservoir into a gas reservoir. J. Pet. Sci. Eng. 2019, 178, 616-628. [CrossRef]

14. Lu, B.X. Numerical simulations of temperature field of coalbed methane with heat injection based on ANSYS. In Proceedings of the 2012 International Conference on Computer Science and Electronics Engineering, Hangzhou, China, 23-25 March 2012; Volume 2.

15. Shahtalebi, A.; Khan, C.; Dmyterko, A.; Shukla, P.; Rudolph, V. Investigation of thermal stimulation of coal seam gas fields for accelerated gas recovery. Fuel 2016, 180, 301-313. [CrossRef]

16. Li, H.; Kang, J.; Zhou, F.; Qiang, Z.; Li, G. Adsorption heat features of coalbed methane based on microcalorimeter. J. Loss Prev. Process Ind. 2018, 55, 437-449. [CrossRef]

17. Miklová, B.; Staf, M.; Kyselová, V. Influence of ash composition on high temperature CO2 sorption. J. Environ. Chem. Eng. 2019, 7, 103017. [CrossRef]

18. Okolo, G.N.; Everson, R.C.; Neomagus, H.W.; Sakurovs, R.; Grigore, M.; Bunt, J.R. The carbon dioxide, methane and nitrogen high-pressure sorption properties of South African bituminous coals. Int. J. Coal Geol. 2019, 209, 40-53. [CrossRef]

19. Sakurovs, R.; Day, S.; Weir, S.; Duffy, G. Temperature dependence of sorption of gases by coals and charcoals. Int. J. Coal Geol. 2008, 73, 250-258. [CrossRef] 
20. Charrière, D.; Pokryszka, Z.; Behra, P. Effect of pressure and temperature on diffusion of CO2 and CH4 into coal from the Lorraine basin (France). Int. J. Coal Geol. 2010, 81, 373-380. [CrossRef]

21. Guan, C.; Liu, S.; Li, C.; Wang, Y.; Zhao, Y. The temperature effect on the methane and CO2 adsorption capacities of Illinois coal. Fuel 2018, 211, 241-250. [CrossRef]

22. Crosdale, P.J.; Moore, T.A.; Mares, T.E. Influence of moisture content and temperature on methane adsorption isotherm analysis for coals from a low-rank, biogenically-sourced gas reservoir. Int. J. Coal Geol. 2008, 76, 166-174. [CrossRef]

23. Zhang, L.; Aziz, N.; Ren, T.X.; Wang, Z. Influence of temperature on coal sorption characteristics and the theory of coal surface free energy. Procedia Eng. 2011, 26, 1430-1439. [CrossRef]

24. Liu, Y.; Zhu, Y.; Liu, S.; Li, W.; Tang, X. Temperature effect on gas adsorption capacity in different sized pores of coal: Experiment and numerical modeling. J. Pet. Sci. Eng. 2018, 165, 821-830. [CrossRef]

25. Akbarzadeh, H.; Chalaturnyk, R.J. Structural changes in coal at elevated temperature pertinent to underground coal gasification: A review. Int. J. Coal Geol. 2014, 131, 126-146. [CrossRef]

26. Niu, S.; Zhao, Y.; Hu, Y. Experimental ivestigation of the temperature and pore pressure effect on permeability of lignite under the in situ condition. Trans. Porous Media 2014, 101, 137-148. [CrossRef]

27. Zhang, X.G.; Ranjith, P.G.; Perera, M.S.A.; Ranathunga, A.S.; Haque, A. Gas transportation and enhanced coalbed methane recovery processes in deep coal seams: A review. Energy Fuels 2016, 30, 8832-8849. [CrossRef]

28. Wang, K.; Du, F.; Wang, G. Investigation of gas pressure and temperature effects on the permeability and steady-state time of Chinese anthracite coal: An experimental study. J. Nat. Gas Sci. Eng. 2017, 40, 179-188. [CrossRef]

29. Yin, G.; Jiang, C.; Wang, J.G.; Xu, J. Combined effect of stress, pore pressure and temperature on methane permeability in anthracite coal: An experimental study. Trans. Porous Media 2013, 100, 1-16. [CrossRef]

30. Perera, M.S.A.; Ranjith, P.G.; Choi, S.K.; Airey, D. Investigation of temperature effect on permeability of naturally fractured black coal for carbon dioxide movement: An experimental and numerical study. Fuel 2012, 94, 596-605. [CrossRef]

31. Teng, T.; Wang, J.G.; Gao, F.; Ju, Y.; Jiang, C. A thermally sensitive permeability model for coal-gas interactions including thermal fracturing and volatilization. J. Nat. Gas Sci. Eng. 2016, 32, 319-333. [CrossRef]

32. Pandey, S.N.; Chaudhuri, A.; Kelkar, S. A coupled thermo-hydro-mechanical modeling of fracture aperture alteration and reservoir deformation during heat extraction from a geothermal reservoir. Geothermics 2017, 65, 17-31. [CrossRef]

33. Tong, F.; Jing, L.; Zimmerman, R.W. A fully coupled thermo-hydro-mechanical model for simulating multiphase flow, deformation and heat transfer in buffer material and rock masses. Int. J. Rock Mech. Min. Sci. 2010, 47, 205-217. [CrossRef]

34. Abed, A.A.; Sołowski, W.T. A study on how to couple thermo-hydro-mechanical behaviour of unsaturated soils: Physical equations, numerical implementation and examples. Comput. Geotech. 2017, 92, 132-155. [CrossRef]

35. Gao, F.; Xue, Y.; Gao, Y.; Zhang, Z.; Teng, T.; Liang, X. Fully coupled thermo-hydro-mechanical model for extraction of coal seam gas with slotted boreholes. J. Nat. Gas Sci. Eng. 2016, 31, 226-235. [CrossRef]

36. Fan, C.; Elsworth, D.; Li, S.; Zhou, L.; Yang, Z.; Song, Y. Thermo-hydro-mechanical-chemical couplings controlling $\mathrm{CH} 4$ production and $\mathrm{CO} 2$ sequestration in enhanced coalbed methane recovery. Energy 2019, 173, 1054-1077. [CrossRef]

37. Xia, T.; Zhou, F.; Liu, J.; Kang, J.; Gao, F. A fully coupled hydro-thermo-mechanical model for the spontaneous combustion of underground coal seams. Fuel 2014, 125, 106-115. [CrossRef]

38. Zhang, R.; Liu, S. Experimental and theoretical characterization of methane and CO2 sorption hysteresis in coals based on Langmuir desorption. Int. J. Coal Geol. 2017, 171, 49-60. [CrossRef]

39. Rani, S.; Padmanabhan, E.; Prusty, B.K. Review of gas adsorption in shales for enhanced methane recovery and CO2 storage. J. Pet. Sci. Eng. 2018, 175, 634-643. [CrossRef]

40. Kim, J.; Jang, Y.; Seomoon, H.; Lee, H.; Sung, W. A new sorption-corrected deconvolution method for production data analysis in a shale gas reservoir containing adsorbed gas. Int. J. Oil Gas Coal Technol. 2019, 20, 55-68. [CrossRef]

41. Zhang, H.; Liu, J.; Elsworth, D. How sorption-induced matrix deformation affects gas flow in coal seams: A new FE model. Int. J. Rock Mech. Min. Sci. 2008, 45, 1226-1236. [CrossRef] 
42. Wu, Y.; Liu, J.; Chen, Z.; Elsworth, D.; Pone, D. A dual poroelastic model for $\mathrm{CO}_{2}$-enhanced coalbed methane recovery. Int. J. Coal Geol. 2011, 86, 177-189. [CrossRef]

43. Liang, B. Study on temperature effects on the gas absorption performance. J. Heilongiiang Min. Inst. 2000, 10, 20-22.

44. Zhu, W.C.; Wei, C.H.; Liu, J.; Qu, H.Y.; Elsworth, D. A model of coal-gas interaction under variable temperatures. Int. J. Coal Geol. 2011, 86, 213-221. [CrossRef]

45. Qu, H.; Liu, J.; Chen, Z.; Wang, J.; Pan, Z.; Connell, L.; Elsworth, D. Complex evolution of coal permeability during CO2 injection under variable temperatures. Int. J. Greenh. Gas Control 2012, 9, 281-293. [CrossRef]

46. Ibrahim, A.F.; Nasr-El-Din, H.A. A comprehensive model to history match and predict gas/water production from coal seams. Int. J. Coal Geol. 2015, 146, 79-90. [CrossRef]

(C) 2019 by the authors. Licensee MDPI, Basel, Switzerland. This article is an open access article distributed under the terms and conditions of the Creative Commons Attribution (CC BY) license (http://creativecommons.org/licenses/by/4.0/). 